\title{
UNA APROXIMACIÓN AL SIGNIFICADO DE ANÁLISIS EXISTENCIAL EN LA LOGOTERAPIA DE VIKTOR FRANKL
}

\section{An approximation to the definition of existential analysis in the Logotherapy of Viktor Frankl}

Luis Alonso Ramos Franco*

\section{Resumen}

En el presente ensayo se pretende iniciar una exploración preliminar del significado de "análisis existencial" dentro de la propuesta de Logoterapia de Viktor Frankl, conceptualizando en concreto las nociones "análisis" y "existencial”, así como el fundamento antropológico que reclama este tipo de aproximación terapéutica. Se mostrará que dicho término busca hacer referencia tanto al fundamento de una psicoterapia como al fundamento del movimiento humano que hace consciente lo espiritual para hallar sentido en la concreción humana, y que finalmente se estabiliza en forma de hábito inconsciente.

Palabras clave: Análisis existencial, logoterapia, psicoterapia, espiritualidad, antropología.

\begin{abstract}
The present essay is intended to initiate a preliminary exploration of the meaning of "existential analysis" in the Logotherapy of Viktor Frankl, conceptualizing specifically the notions of "analysis" and "existential" as well as the anthropological foundation that this type of therapeutic approach claims. It will be shown that the term "existential analysis" seeks to evoke both the foundation of a psychotherapy as well as the foundation of a human movement that becomes conscious in order to find spiritual meaning in the human concreteness, and that it finally stabilizes in the form of an unconscious habit.
\end{abstract}

Keywords: Existential analysis, logotherapy, psychotherapy, spirituality, anthropology.

\footnotetext{
* Estudiante de la Escuela Profesional de Psicología de la Universidad Católica San Pablo, Arequipa-Perú. laramos@ucsp.edu.pe
} 


\section{INTRODUCCIÓN}

Viktor Frankl (1905 - 1997) fue el iniciador de la Tercera Escuela Vienesa de Psicología, la Logoterapia. Neurólogo de profesión, se interesó por la filosofía y el psicoanálisis desde joven, lo cual perfiló su camino hacia la psiquiatría. Entre 1942 y 1945, al ser víctima de los arrestos nazi, sobrevivió en distintos campos de concentración, entre los cuales se incluye Auschwitz. El haber experimentado en carne propia el horror del Holocausto fue para él no sólo uno de los más grandes sufrimientos de su vida, sino también un evento existencial que revistió su ser y quehacer psicológicos de un profundo sentido. Frente al psicoanálisis de Freud y la psicología individual de Adler, Frankl propone el análisis existencial como fondo intelectual y metodológico de una psicoterapia fundamentada en la búsqueda y expresión de sentido. La Logoterapia, como indica nuestro autor, «se ve en la situación de afrontar problemas filosóficos del paciente que surgen de él mismo» (Frankl, 1987b). Sin embargo, veremos que "encontrar sentido" presupone una dimensión antropológica distinta de lo biológico e incluso de lo psicológico. Por eso mismo, la palabra "logos" hace referencia tanto a la palabra sentido, como a lo mental en cuanto dimensión distinta de lo psicológico, y más propiamente a «un inconsciente mental y el logos, al que la conformación terapéutica del análisis existencial, la logoterapia, convierte tanto en el hacia dónde y en el de dónde de sus esfuerzos» (Frankl, 1987a). En el presente ensayo se pretende iniciar una exploración del significado de "análisis existencial" dentro de la propuesta de Logoterapia de Viktor Frankl.

\section{CONCEPTUALIZACIÓN DEL ANÁLISIS EXISTENCIAL}

¿Qué significa para nuestro autor el concepto de "análisis existencial"? Influenciado por Martin Heidegger y Karl Jaspers, Frankl utilizará este término con un matiz propio. En cuanto a la palabra existencial, dirá lo siguiente: «en esta fórmula, existencial significa una forma de ser y en especial el carácter propio del hombre. Para esta forma especial de la existencia $(D a-$ sein) la filosofía contemporánea reserva la expresión existencia (Existenz), y nosotros, en el análisis existencial y en la logoterapia, hemos tomado prestada esta expresión con este contenido» (Frankl, 1987a). Para comprender esta noción en cuanto forma de ser o carácter propio del hombre, es necesario aclarar qué significa la expresión "existir" para el ser humano: «"Ex-sistir" quiere decir salir de sí mismo y ponerse frente a sí mismo, de manera que el hombre sale del nivel de lo corporal psíquico y llega a sí mismo pasando por el ámbito de lo espiritual. La existencia acontece en el espíritu» (Frankl, 1987a). Notamos inmediatamente que, por un lado, se trata de un movimiento de salida y otro de ponerse frente a sí mismo, al mismo tiempo que la noción de "espíritu" o "lo espiritual" se torna imprescindible para comprender qué es lo propio del hombre. Como él mismo indica, «en el momento en que introdujimos el término "análisis existencial" en 1938, la filosofía contemporánea ofrecía el término "existencia" para denotar el modo específico del ser que se caracteriza básicamente por su capacidad de ser responsable» (Frankl, 1997). En efecto, lo más originariamente específico en la existencia humana sería el poder ser responsable, y esto se logra mediante un movimiento de salida de sí mismo que lleva a la persona a ponerse frente a sí misma. Esta dinámica acontece en una dimensión personal llama "espíritu" -distinta de lo psicológico y lo biológico-, y es esto lo que diferencia a las personas de los animales y demás objetos del mundo material. En el concepto de "análisis existencial" la palabra "existencial", por lo tanto, hace referencia a todo esto. Podríamos decir que se trata de un análisis del movimiento de salida de sí mismo para poder ponerse frente a uno mismo, a fin de conseguir que la persona exprese lo más propio de sí, su capacidad de ser responsable.

En relación a la palabra "análisis" también es necesario clarificar ciertas nociones. En primer lugar, el análisis como antónimo de síntesis no es propiamente aquello a lo que Frankl se refiere. No se trata de descomponer los elementos de un todo orgánico para estudiarlos por separado, como la palabra parecería indicar. De hecho, aunque inicialmente suene paradójico, para Frankl analizar la existencia humana es tan imposible como pretender sintetizarla, y esto se debe principalmente al carácter irreductible del ser del hombre: «en el fondo, no es ningún análisis de la existencia, puesto que un análisis de la existencia no existe como tampoco existe una síntesis de la existencia. [...] Es más bien explicación de la existencia» (Frankl, 1987a). Así, el análisis existencial no significa "análisis de la existencia", sino un análisis orientado a la 
existencia, es decir, más que intentar conceptualizarla, explicar la existencia significa dar un fundamento antropológico que exprese el ser propio del hombre, dado siempre en una situación concreta, o como él diría prestándose una expresión heideggeriana, ofrecer una antropología del Dasein: se trata de un «intento de una antropología psicoterapéutica, de una antropología que preceda a cualquier psicoterapia»-por esta razón Frankl tendrá al análisis existencial como fundamento intelectual de la Logoterapia. Siguiendo esta lógica, hacer un "análisis" existencial significa intentar dar fundamento a la existencia humana.

Sumando esta noción a lo previamente dicho en relación a la palabra "existencial" podemos decir que, "análisis existencial" significa intentar dar un fundamento antropológico del movimiento que va de sí mismo hacia fuera de sí mismo para ponerse frente a sí mismo, de tal forma que la persona pueda ejercitar su dimensión espiritual y poner en acto su capacidad de responsabilidad. En palabras más simples significa hacer relucir el sentido auténtico que tiene el existir en cuanto persona humana.

\section{NECESIDAD ANTROPOLÓGICA DEL ANÁLISIS EXISTENCIAL}

Utilizando nuevamente nociones filosóficas propias de su época, Frankl indicará que los tres "existenciales" que caracterizan y constituyen el existir auténticamente humano son: espiritualidad, libertad y responsabilidad (Frankl, 1987a). Estas tres palabras expresan lo más hondo, originario y esencial del existir del ser humano, diferenciado del mundo animal y material. Se trata de nociones estrechamente vinculadas y que en ocasiones parecen confundirse. Algo que caracteriza mucho a Frankl en relación a Freud y Adler es que nuestro autor hace un esfuerzo muy sistemático por ofrecer a su terapia una sólida fundamentación antropológica. Él mismo se ha dado el trabajo de establecer los límites y las diferencias de su propuesta en relación al psicoanálisis. Dirá de éste:

Poseedor como es de un punto de vista tan atomista, energético y mecanicista del ser humano, el psicoanálisis se define como el automaton de un aparato físico. Y en este punto es donde el análisis existencial tiene algo que decir. Propone un concepto del hombre diferente, y opuesto al del punto de visto psicoanalítico. No se centra en el automaton de un aparato físico, sino más bien en la autonomía de la existencia espiritual (Usamos aquí el término "espiritual" sin connotación religiosa alguna, sino más bien con la intención de poner de manifiesto que hablamos de una cuestión referente a fenómenos específicamente humanos, en contraste a fenómenos que podemos compartir con otros animales. En otras palabras, lo "espiritual" es lo que hay de humano en el hombre (Frankl, 1997).

Existencia humana es, entonces, existencia espiritual. Continuando con los paralelismos con el psicoanálisis encontramos que también existe una comparación entre la dinámica consciente-inconsciente a la que el psicoanálisis da tanta importancia. En la concepción antropológica de Freud el ser humano era un híbrido entre fuerzas instintivas y regulaciones mecánicas inconscientes. A semejanza de Freud, Frankl también identifica un inconsciente instintivo, pero además el psiquiatra vienés encuentra un inconsciente espiritual o una espiritualidad inconsciente en el ser humano. Es más, para él «la existencia es esencialmente inconsciente, ya que los cimientos de la existencia no pueden reflejarse plenamente en ella misma, y tampoco pueden tener del todo consciencia de sí misma» (Frankl, 1997). Si la existencia hace referencia al movimiento espiritual de salida de sí para ponerse frente a sí mismo en un acto de responsabilidad, podemos decir que el origen de este movimiento, el principio que anima esta dinámica, está siempre en el ámbito de lo inconsciente: «en sus orígenes, el espíritu humano es un espíritu inconsciente» (Frankl, 1997). Vale la pena agregar que, en este marco teórico, tanto la conciencia como la responsabilidad son cada una un Urphänomen, es decir, fenómenos al mismo tiempo irreductibles al análisis e inherentes al ser humano (entscheidendes Sein). Así, retomando la explicación del concepto de "análisis", la propia naturaleza humana necesita expresarse en un movimiento que va de lo inconsciente a lo consciente y viceversa, y este movimiento posee intrínsecamente un sentido, el cual se muestra en el instante en que lo potencial pasa a ser actual, es decir, en el momento en que la persona ejercita su dimensión espiritual se muestra inmediatamente el sentido de su existencia situada, o bien, de su esencia en general y de la 
situación concreta por la que está atravesando. Así, la antropología frankliana reclama un análisis existencial para poder manifestar el sentido que le es inherente.

\section{EL ANÁLISIS EXISTENCIAL EN LA LOGOTERAPIA}

Frankl (1997), en un juego de palabras, dirá que Freud ha "id-ificado" (id = "ello") la existencia humana, degradando el "sí mismo" -el cual sería sólo un epifenómeno de un mecanismo instintivo-, mientras quesu propuesta terapéutica,juntoalanálisisexistencial, buscaría revelar lo auténticamente humano -más allá de las distorsiones psicóticas y neuróticas-, y llevar a que la persona lo exprese responsable y plenamente. Así, si pudiesen diferenciarse logoterapia y análisis existencial diríamos con Frankl que «la logoterapia es un método de tratamiento psicoterapéutico mientras que el análisis existencial representa una orientación antropológica de investigación [que en cuanto tal está] abierta en dos direcciones: está dispuesta a la cooperación con otras orientaciones y a su propia evolución» (Frankl, 1987b). Su objeto principal es la dimensión noológica (de nous, "espíritu"), es decir, en la dimensión espiritual. Insertada en la logoterapia, hace de ella un método psicoterapéutico en cuanto «se preocupa de la forma neurótica de ser y está orientada a ofrecer al hombre (en especial, al neurótico) una toma de conciencia de su propia responsabilidad» (Frankl, 1997). Se puede notar una cierta herencia del psicoanálisis, en el sentido de que aquí también se toma conciencia de algo, pero no del instinto, sino de lo espiritual o existencial; en otras palabras, la responsabilidad personal: «el análisis existencial interpreta la existencia humana, y más allá, el ser humano, en términos de un ser responsable» (Frankl, 1997). Y así también, si en la concepción freudiana la persona está determinada por lo instintivo, con el análisis existencial se busca que la persona asuma la necesidad de determinarse con sentido, es decir, que se vuelva responsable.

Mientras que Freud haría emerger a la conciencia el "ello", en la logoterapia, gracias al análisis existencial, lo que emerge es el "sí mismo" en cuanto conciencia de sí mismo. Tener conciencia de sí significa haber sido apelado por el sentido de la propia responsabilidad, es decir «el análisis existencial, en tanto que es psicoterapia o tan pronto como llega a ser logoterapia, descubre no sólo lo espiritual, sino que apela también a esta espiritualidad, apela a una potencia resistente espiritual» (Frankl, 1987a). Se dice que esta potencia es resistente porque, frente a la distorsión de una psicosis, por ejemplo, emerge a la luz aquello que en el sujeto permanece inalterado, lo más propio de sí, el sí mismo, lo espiritual: «señalar y sacar a relucir lo personal en la psicosis es el propósito del análisis existencial» (Frankl, 1987a). Esto no es más que la operación por medio de la cual, a través de una recta fenomenología, se distingue el cuadro de la enfermedad de la verdadera imagen personal del hombre, es decir, el psicoanálisis abre una suerte de espacio metaclínico que distingue fenómenos y síntomas de enfermedades neuróticas y psicóticas, de la humanidad de la persona, que es en sí misma intocable y se encuentra como un substrato, es decir, yace detrás de toda disolución creada por una neurosis o psicosis. Esto implica también identificar aquellas circunstancias en que una psicosis, y gracias a ella, se pueda activar en la persona una espiritualidad que yacía inconsciente. Sin embargo, una persona cuya psicosis alce tales barreras que impidan al psicoterapeuta fijar su vista en la persona en sí misma, es inmune a la apelación que genera el análisis existencial: «sólo es aplicable un procedimiento logoterapéutico en casos de psicosis clínicamente leves o medio graves» (Frankl, 1987a).

En el análisis existencial también es importante distinguir entre lo que significa "dar" sentido y "encontrar" sentido. No se trata de atribuir arbitrariamente significado a algo, sino de descubrir y despertar algo. Se descubre la humanidad intacta y se despierta la responsabilidad y la libertad de la persona, recordando los tres "existenciales" que Frankl atribuye al existir humano en cuanto humano. Al decir esto se entiende que el tipo de respuesta no puede ser pasiva. Antes bien, ante aquello que se revela el ser humano ha de tomar una postura, la cual implica ponerse en movimiento -salir de sí para ponerse frente a sí mismo. En este sentido, la persona se topa con una interrogante que le es lanzada no por sí mismo o alguien más -el psicoterapeuta por ejemplo-, sino por la realidad misma que le exige de alguna manera dar una respuesta-en acción: 
No es el hombre quien hace la pregunta "¿Cuál es el sentido de la vida?", sino que es a él a quien se le hace esta pregunta, ya que es la vida misma quien se encarga de hacer esta pregunta. $\mathrm{Y}$ el hombre tiene que contestarle a la vida con una respuesta que sea su vida misma; tiene que contestarle siendo responsable; en otras palabras, la respuesta es necesariamente una respuesta-en acción (Frankl, 1997).

Esto significa responder en el "aquí y ahora", implicando la concreción de la persona y su situación. La responsabilidad del ser humano es siempre «una responsabilidad ad personam y ad situationem ᄀ» (Frankl,1997).Alhablarde "acción" se hace referenciaa aquella potencialidad que yacía inconsciente, es decir,la espiritualidad que posee y percibe sentido, fundamento. En cierto modo se trata de "activar al ser humano", es decir activar «la conciencia de la responsabilidad personal, la experiencia vivida de su misión especial. Y aquí reside la utilidad psicoterapéutica incomparable y exquisita de un análisis de la existencia como ser responsable» (Frankl, 1987b). Nuevamente podemos notar ciertas analogías con la filosofía existencial de la época, especialmente, en este caso, en relación a la noción de "existencia auténtica". La autenticidad humana se expresa al discernir «si un determinado fenómeno es espiritual o instintivo, mientras que saber si es consciente o inconsciente se convierte en algo relativamente irrelevante» (Frankl, 1997), ya que el ser humano en esta concepción antropológica, no está determinado por impulsos, sino que es responsable de su propia experiencia, es decir, es existencialmente responsable.

Por otro lado, cabe señalar que también es posible que haya una existencia auténtica aunque sea inconsciente -por ejemplo las virtudes-, pero el ser humano en sí mismo será auténtico en la medida en que no se transforme en un producto de sus impulsos, sino que se haga responsable. ¿Se puede hablar entonces de una responsabilidad inconsciente? Aunque suene algo contradictorio, se trata de una responsabilidad que se ha hecho hábito. Si por un lado Frankl (1997) afirma que «vivir bajo la propia conciencia significa siempre vivir en un nivel más elevado a nivel personal, tomando conciencia de la plena concretitud de cada situación», por otro lado existen dimensiones de la existencia humana a las cuales les es propio y natural permanecer en el ámbito de lo inconsciente, y esto sería la expresión más perfectamente humana de sí mismas. Así, por ejemplo, ante un fenómeno de "hiperreflexión" - cuando una persona lleva al mundo consciente algo que no debía, como por ejemplo una atención consciente del mecanismo de creatividad que anima la expresión artística de un violinista, truncando la espontaneidad con la que naturalmente se sabía expresar con su instrumento musical- la terapia aplicaría convenientemente una técnica llamada "derreflexión" orientada a que el paciente recupere la confianza perdida en la capacidad y funcionalidad del inconsciente, inhibidas por una reflexión innecesaria. Al plantear el auténtico objetivo de la psicoterapia Frankl (1997) dirá: «Hay que hacer consciente lo inconsciente -incluyendo el inconsciente espiritual- pero sólo con el objetivo de volver hacia lo inconsciente». El movimiento que se perfila es el siguiente: una potencia que primariamente era inconsciente - por ejemplo la potencia de ser crítico con los propios pensamientos depresivos-, se ha de convertir luego en un acto consciente -por ejemplo el esfuerzo consciente por superar los pensamientos de ese tipo con un análisis del sentido que tiene la propia vida-, para finalmente transformarse a la larga en un hábito inconsciente -por ejemplo la virtud del coraje ante los altibajos depresivos.

Para ayudar al paciente en este ejercicio logoterapéutico, el terapeuta ha de saber señalar ciertas direcciones morales, a diferencia de lo que usualmente se considera que debería ser la actitud profesional. Según indica Frankl, «se ha vuelto a probar continuamente que la misma neurosis tiene su raíz, en última instancia, en lo mental, es decir, que surgió o se mantiene a causa de ciertas posiciones cosmovisivas. Por tanto, es importante intervenir en este ámbito de concepciones personales y valores del paciente, es decir, es importante que el médico evalúe [y que establezca] valores éticos como tales y servir a la ética» (Frankl, 1987b). Es lícito y necesario que el terapeuta sepa ayudar al paciente a confrontar su propia cosmovisión, la cual no deja de ser siempre una concepción moral de la existencia.

Recordando que existir significa salir de sí mismo -y que en el análisis existencial la persona 
sale de sí misma para ponerse frente a sí misma-, ante una cuadro depresivo, por ejemplo, la persona es conducida responsablemente a hacerle frente a su situación, es decir, que exprese su dimensión espiritual que trasciende la depresión y encuentra sentido: «que un hombre se distancia de su depresión endógena, mientras que otro se deja caer en ella, no depende de la depresión endógena sino de la persona espiritual» (Frankl, 1987a). Esto se puede llevar a cabo mediante una virtud que en análisis existencial Frankl denomina "fuerza de obstinación del espíritu", una confrontación que tiende a una reconciliación. Para ello, la técnica del "autodistanciamiento" es así mismo pertinente, ya que por medio de ella la persona puede distanciarse de sí misma en cuanto a su dimensión psicofísica para hacer consciente a la persona espiritual como tal: «sólo cuando el hombre se confronta consigo mismo, lo espiritual y lo corporal-psíquico se separan» (Frankl, 1987a), aclarando que no se trata de descomponer al hombre en sus tres dimensiones, sino de ubicar el origen existencial que da fundamento y encuentra sentido responsable.

\section{CONCLUSIÓN}

Se ha mostrado en este trabajo exploratorio y preliminar cuál es el significado de las nociones "análisis" y "existencial", así como el fundamento antropológico que reclama este tipo de aproximación terapéutica.Además de ello, se ha visto de qué manera se inserta el análisis existencial en la Logoterapia misma. Queda por revisar puntualmente los cinco aspectos que Frankl (1987a) agrupa en el análisis existencial y la logoterapia: 1) Análisis existencial como explicación de la existencia personal; 2)Análisis existencial como terapia de neurosis colectivas; 3) Análisis existencial comocurade almas médica;4)Logoterapiacomoterapia específica de neurosis noógenas; 5) Logoterapia como terapia no específica. Sin embargo se ha conseguido esclarecer que «el objetivo del análisis existencial como explicación antropológica de la existencia personal consiste en hacer consciente, en explicar, en desplegar, en desarrollar la concepción implícita, inconsciente, que la psicoterapia tiene del hombre» (Frankl, 1987a). Es, al mismo tiempo, fundamento de una psicoterapia y fundamento del movimiento humano que hace consciente lo espiritual para hallar sentido en la concreción humana, y que finalmente se estabiliza en forma de hábito inconsciente. De ninguna manera se trata de un análisis de tipo descriptivo solamente, sino de un acompañamiento que lleva al paciente a una confrontación y a un hacerle frente a su situación. Restaría analizar casos concretos de esta aplicación, estudios científicos que le den soporte, y quizá sería conveniente también revisar las bases filosóficas y neurológicas que están implicadas en las dinámicas descritas por Frankl. No obstante, la rica fundamentación filosófica y la aguda intuición humana y existencial que pueden apreciarse en el fundador de la Tercera Escuela Vienesa de Psicología pueden en sí mismas defender y sostener una teoría que ha mostrado ser no sólo efectiva, sino profundamente humana, enfocando el punto nodal de muchas perturbaciones psicológicas: la falta de sentido para la propia existencia.

\section{REFERENCIAS}

Frankl, V.E.(1987). Logoterapia y análisis existencial, Barcelona: Herder.

Frankl, V. E. (1987). Teoría y terapia de la neurosis, Barcelona: Herder.

Frankl, V.E. (1997). El hombre en búsqueda de sentido, Barcelona: Paidós. 